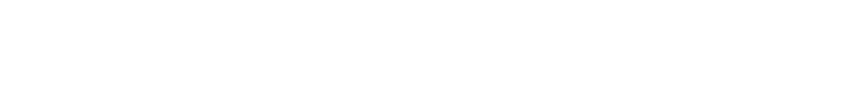

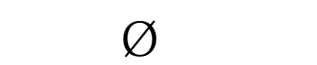

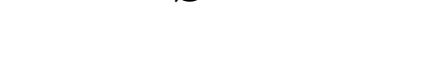

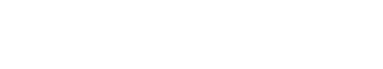

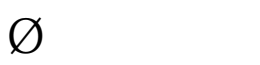

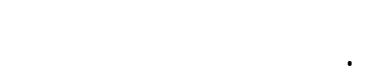

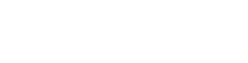

Fożỵ̣̂ Ū

:ŭ Ěr̆̄̌̃KE

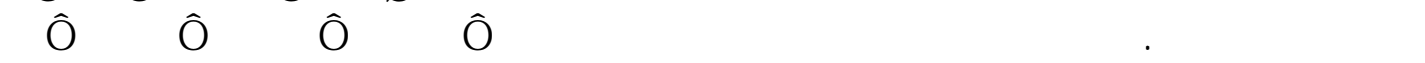

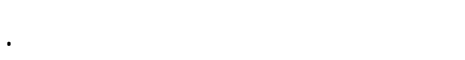

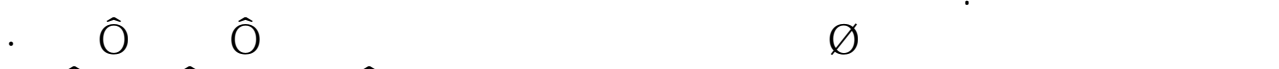

nUU

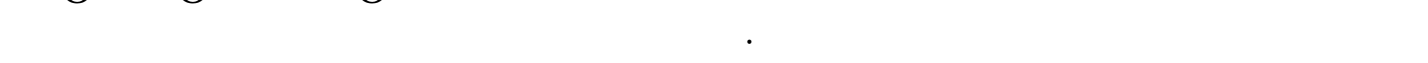

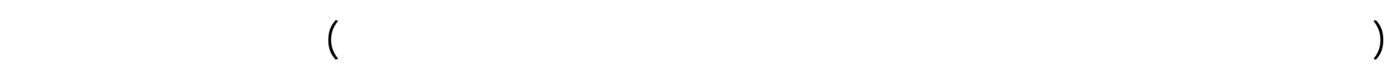

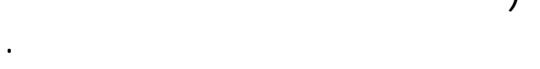

\section{The Proportional Relationships System In Islamic Architecture}

\author{
Dr. Abdullah Y. Al-Tayib \\ Assistant Professor \\ Kadem Fadel Al-ali \\ Master in Architecture \\ Department of Architecture \\ University of Mosul
}

\begin{abstract}
The study defines the research problem as a reconsideration or reformulation of the researches to study of the formation basics of the proportional relationships in Islamic architecture. The aim of the study has been determined through the discovery of the terms and concepts in the proportional relationships system.

The conclusion that have been achieved showed the originality for the proportional relationships system in the Islamic architecture, which based on the aesthetic taste that related to the symbolic aesthetic systems and the acquired knowledge that related to the geometrical mathematics systems for Muslims, and that how the compositions of the Islamic architecture of the difference in it's architectural models, with the it's functional types and it's architectural styles, through one main united though for the formation based on proportional relationships system.
\end{abstract}




\begin{tabular}{llll} 
Al-Rafidain Engineering & Vol.14 & No.2 & 2006 \\
\hline
\end{tabular}

Keyword: Proportion Theory, Geometric Principles, Al-Armawi.

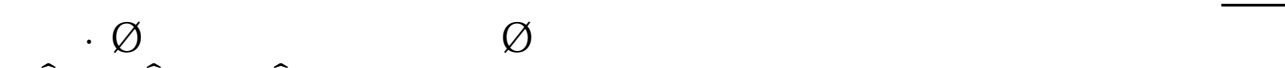

:Th. 1

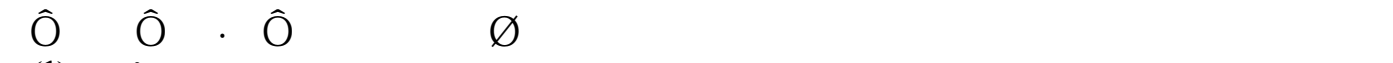

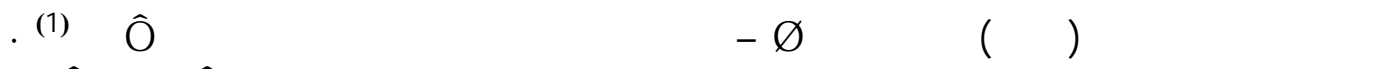

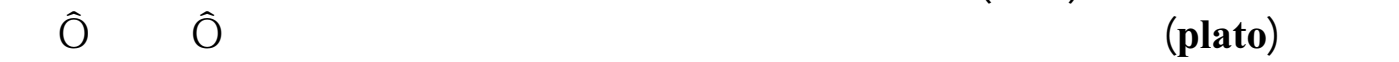

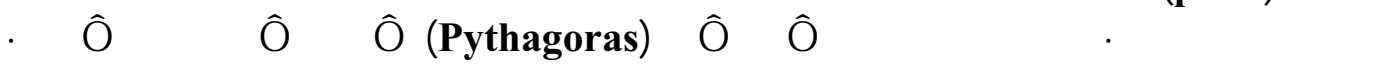

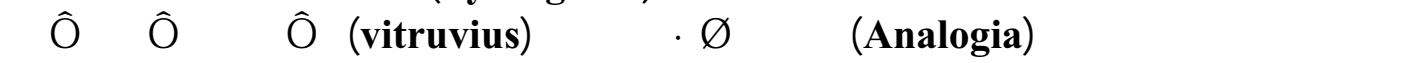

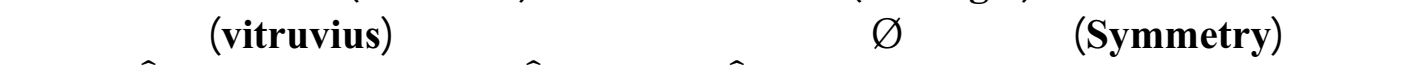

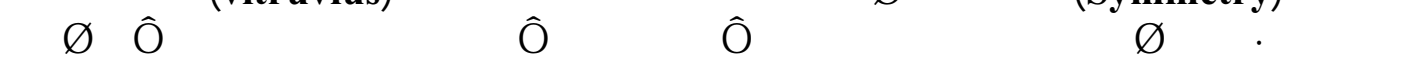

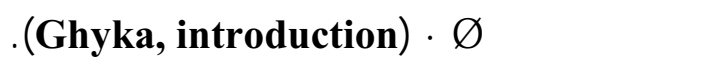
Roㅇ Ū 3/Т̆ Oด

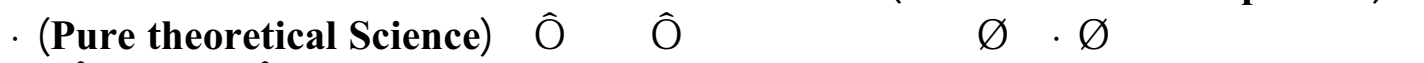

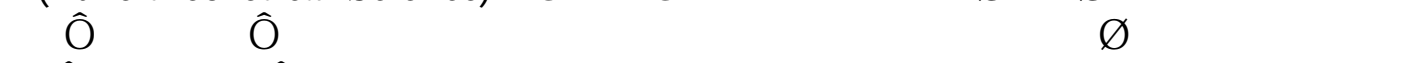

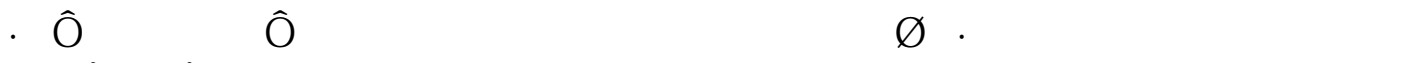

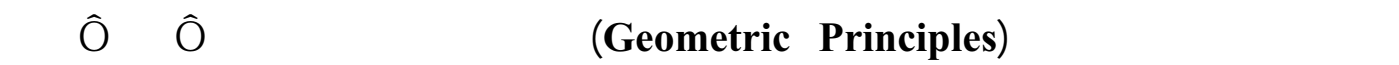

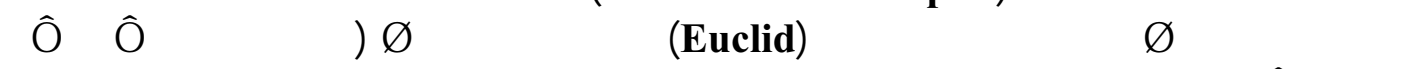
.(Geadel, p.20) $\square$ (b90) Fờ̇(tü)

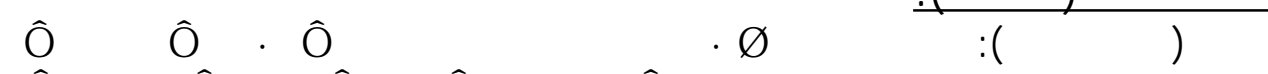

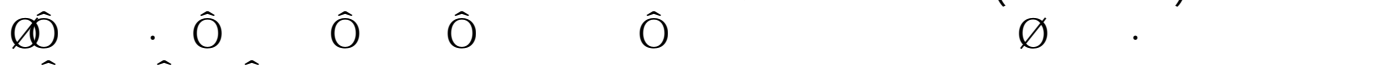

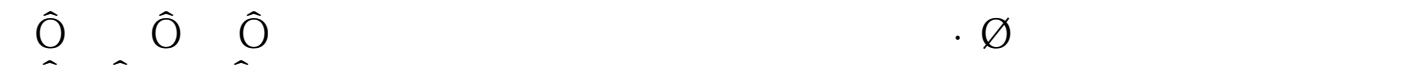

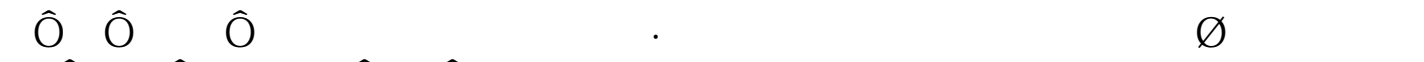

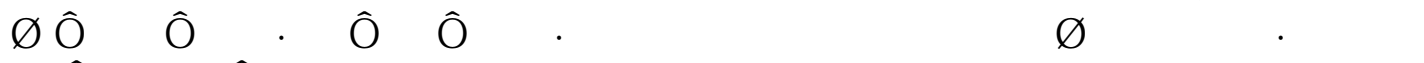

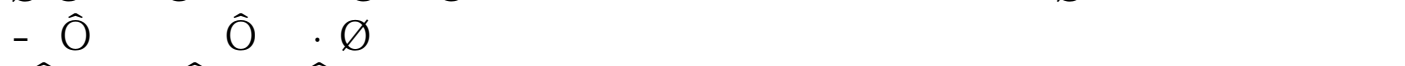

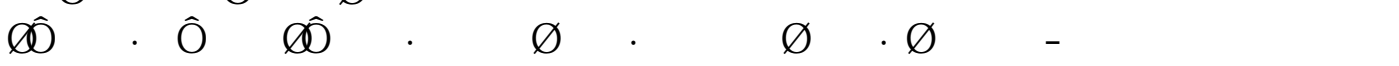

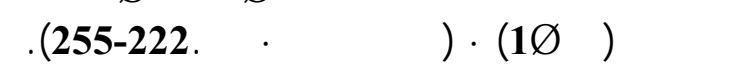

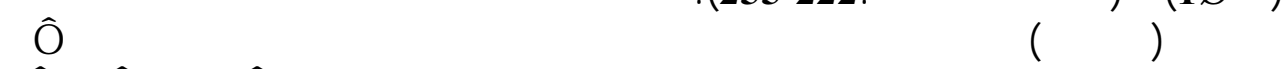

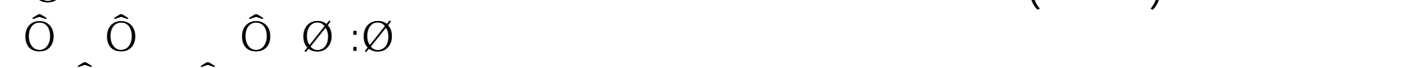
पt

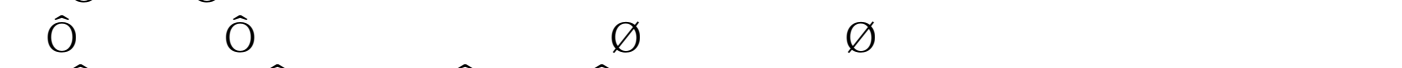
Żố Úh

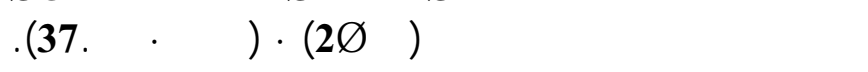

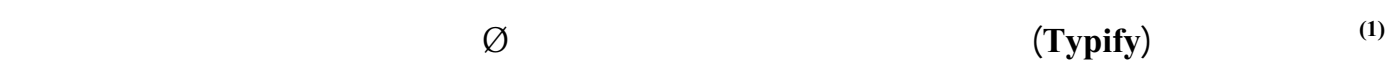

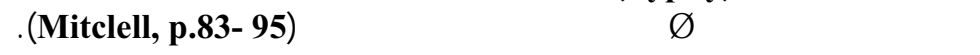




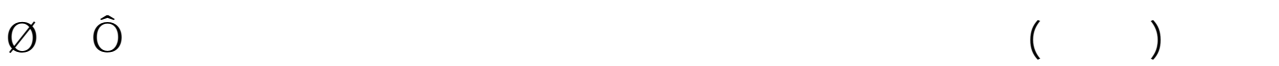

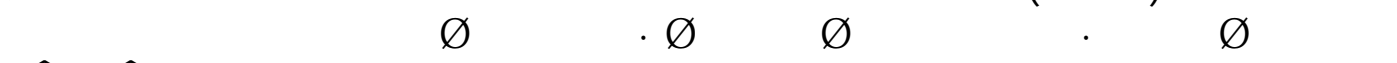

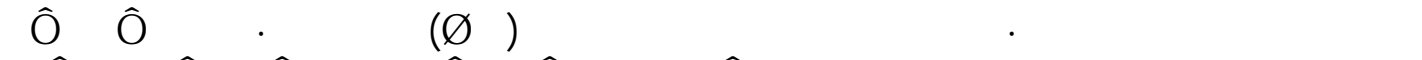
Nữ ȘKG

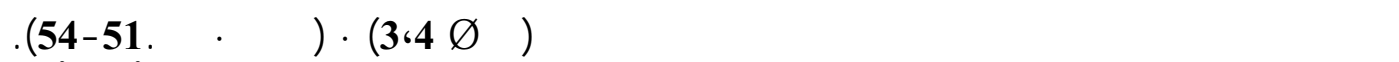

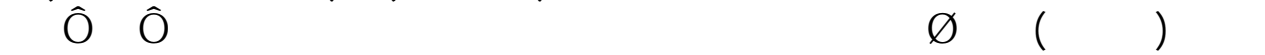

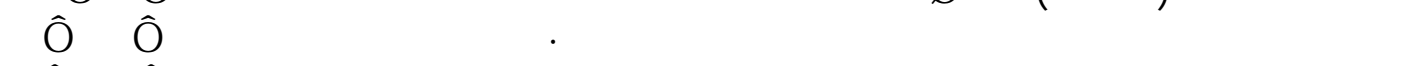

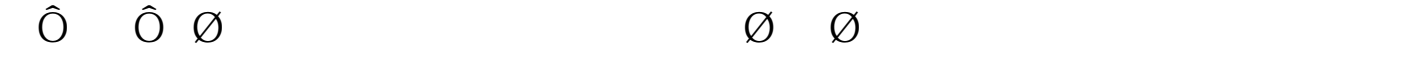

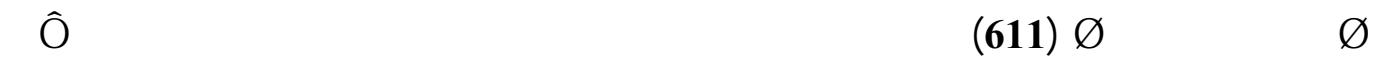

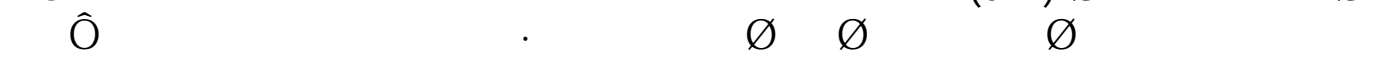

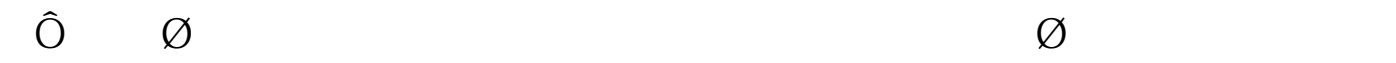

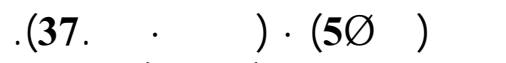

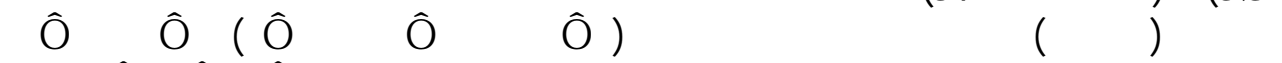

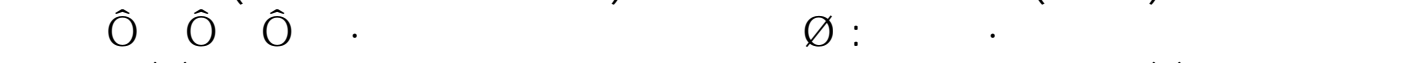

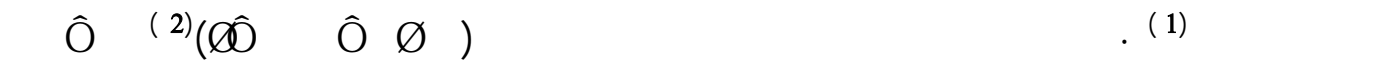

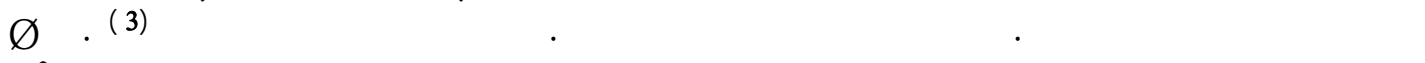

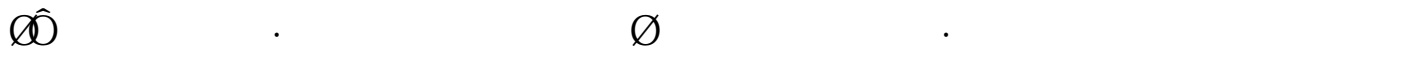

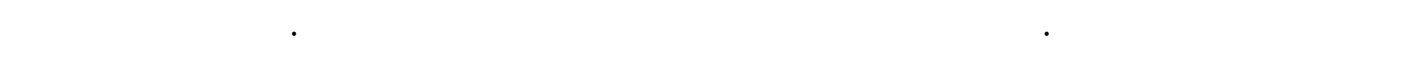

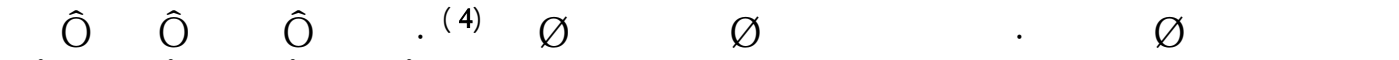

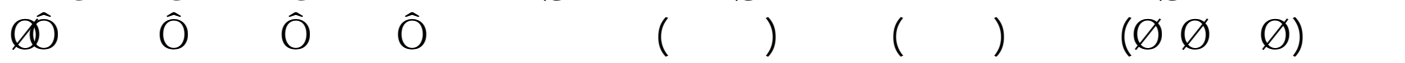

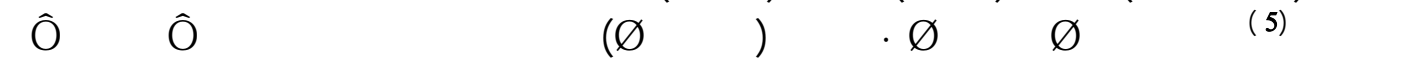

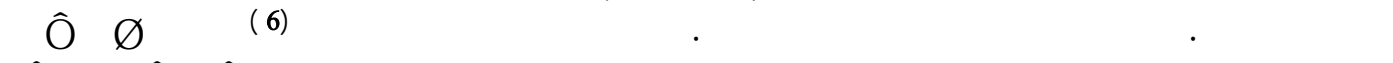

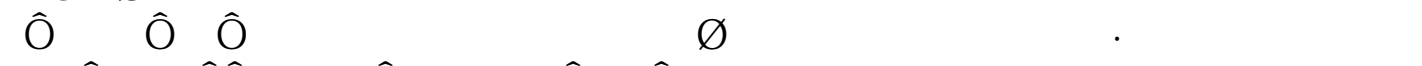

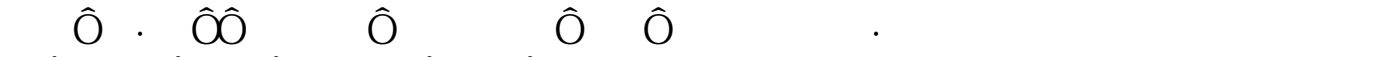

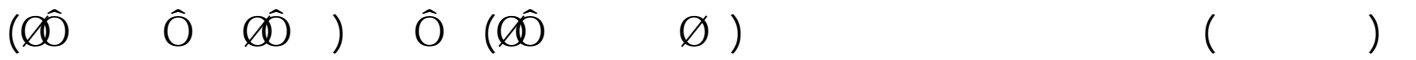

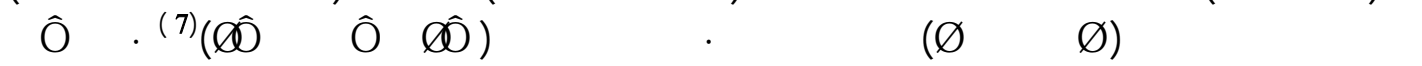
( 8) (3/2)

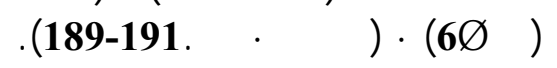

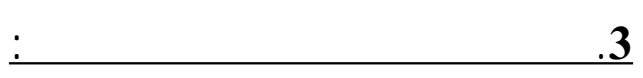

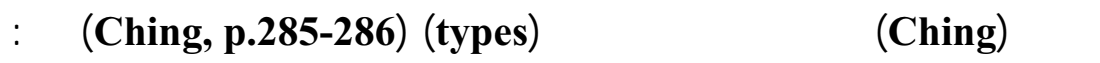

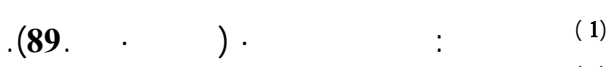
.(90-89.ŭ [F' tof fũ

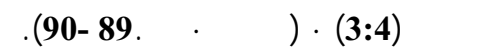

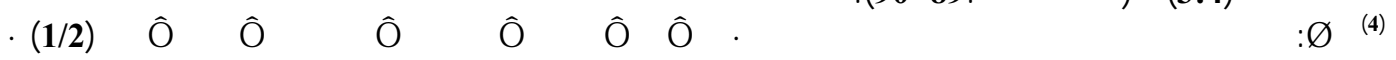

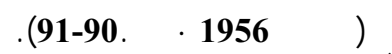

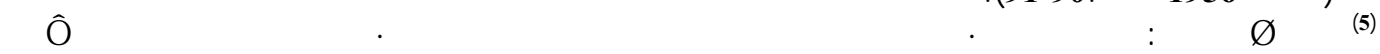
.(91-90.ŭ [Fí⿴囗十) (1/3)

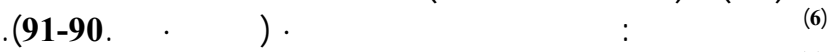

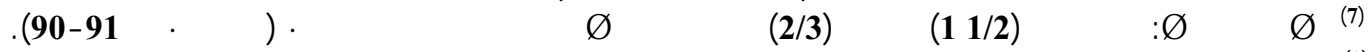

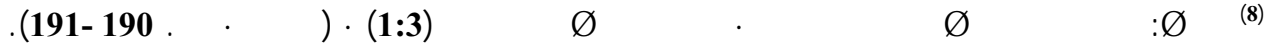




\begin{tabular}{llll} 
Al-Rafidain Engineering & Vol.14 & No.2 & 2006 \\
\hline
\end{tabular}

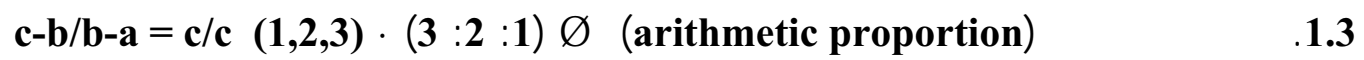

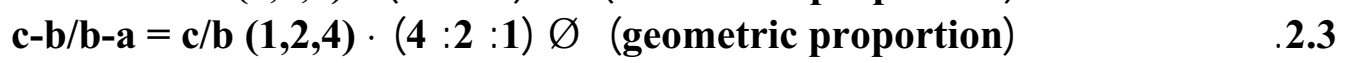

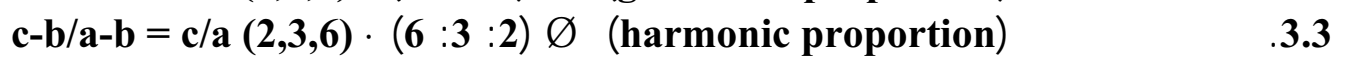

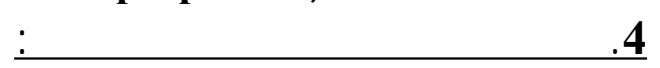

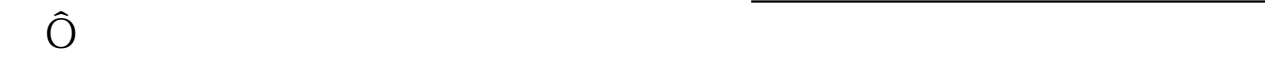

.FEั

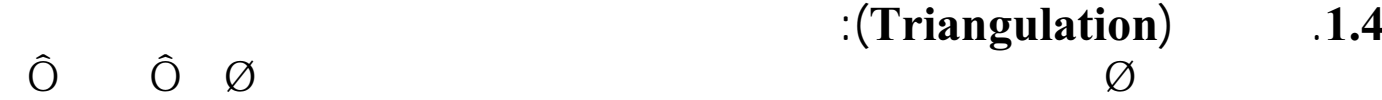

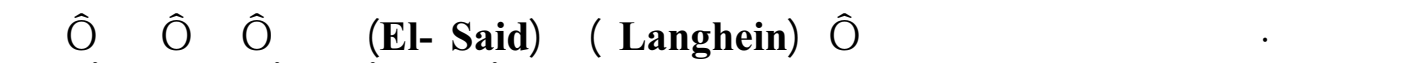
$\square$ ut oÛh

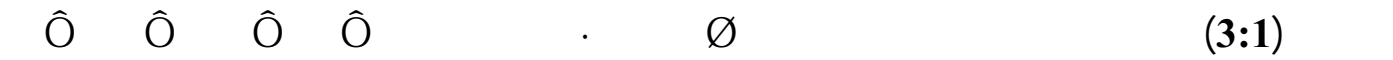

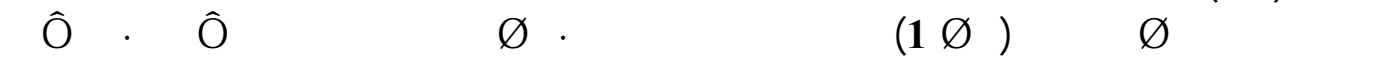

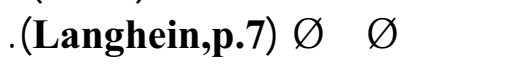

$$
\text { :(Quadratue) Vifter.4 }
$$

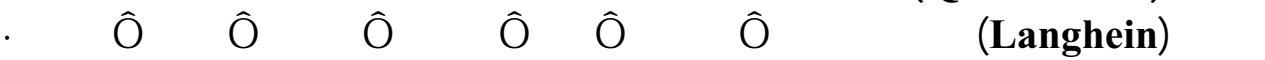

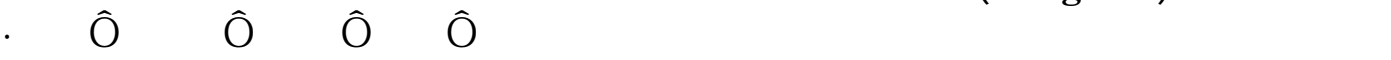

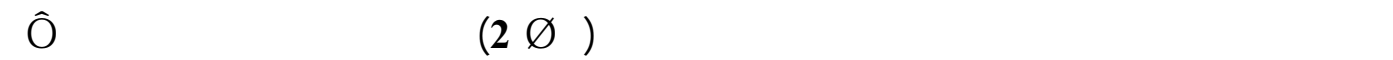

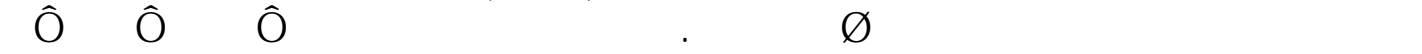

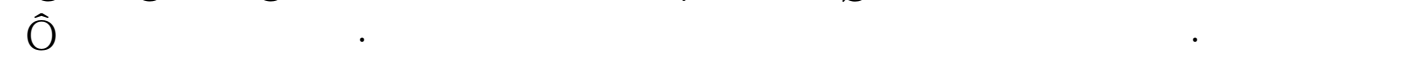

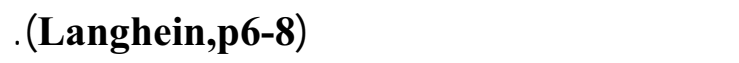

:(Quinture) ŻûdílakB.4

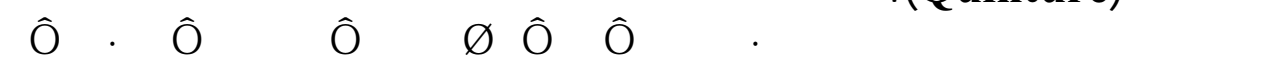

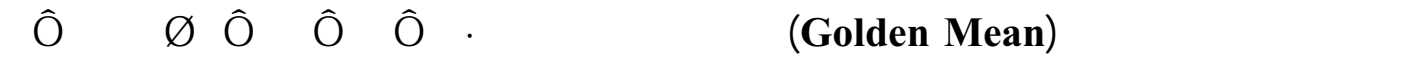

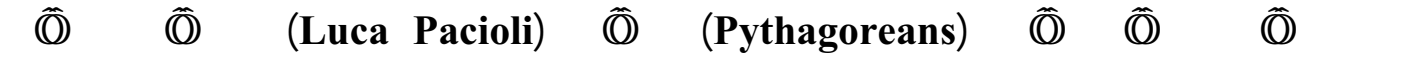

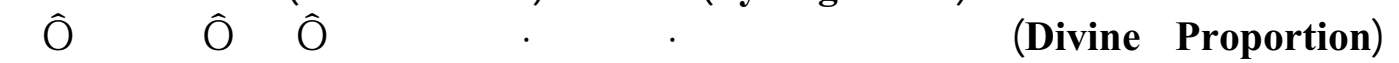

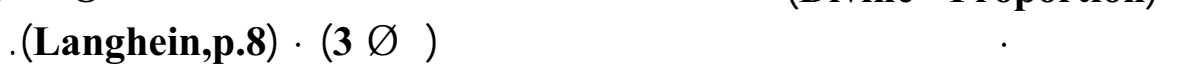

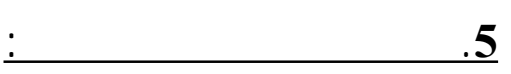

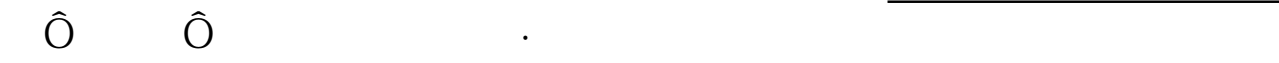

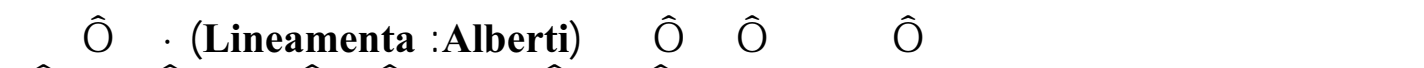

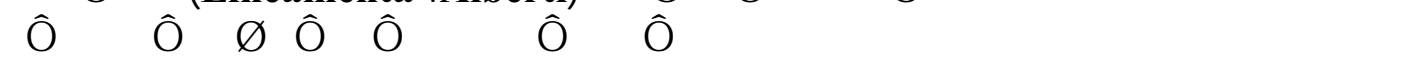

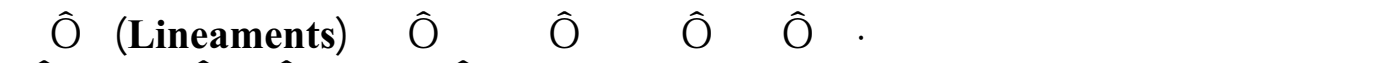

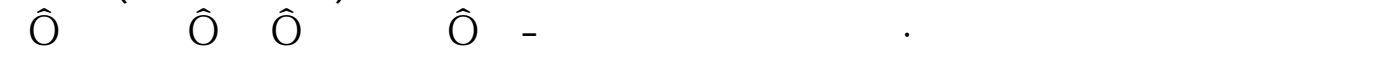




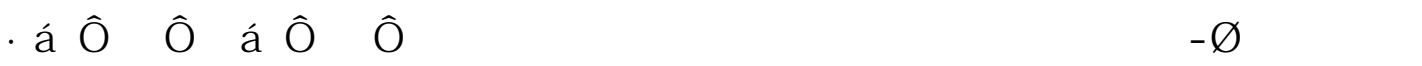

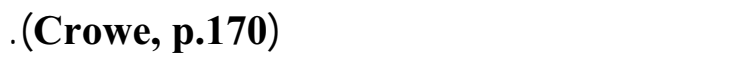

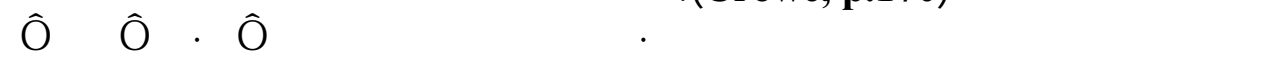

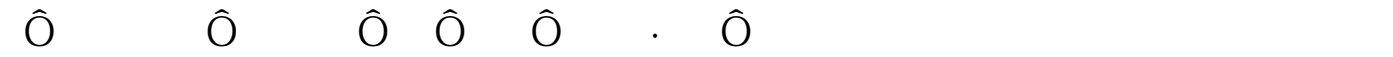

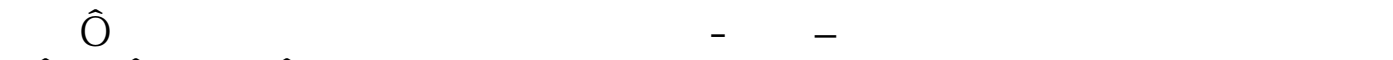

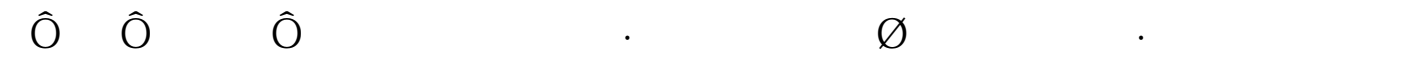

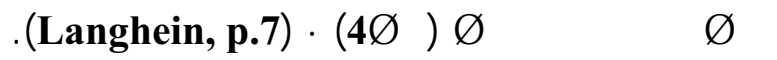

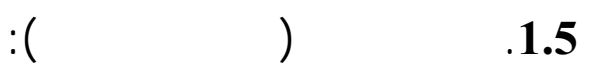

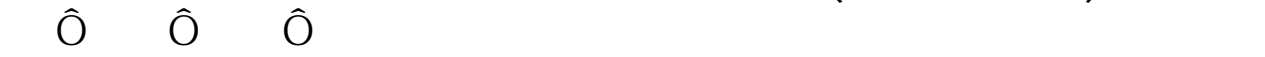
(Ć⿴囗大

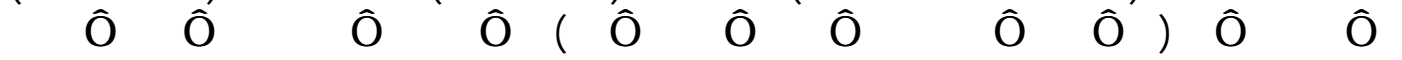

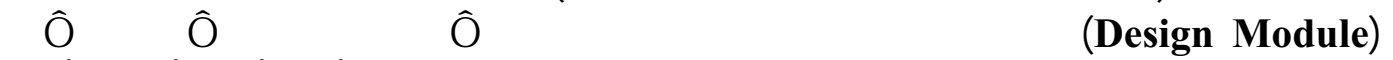

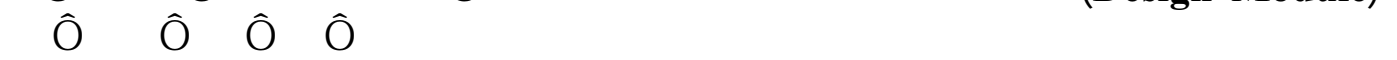

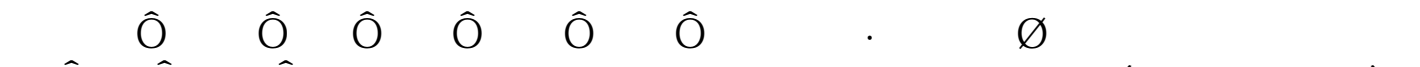

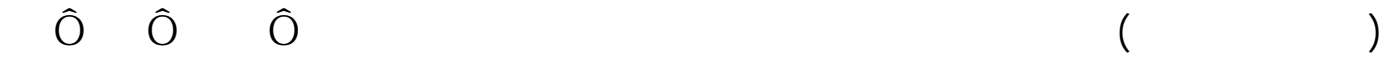

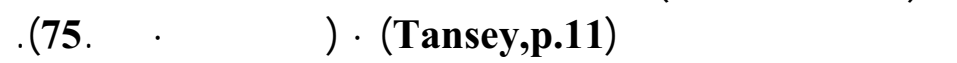

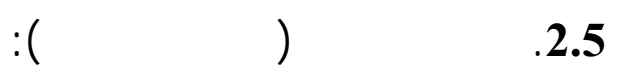

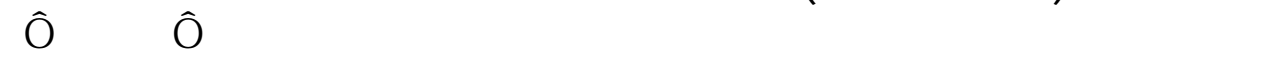

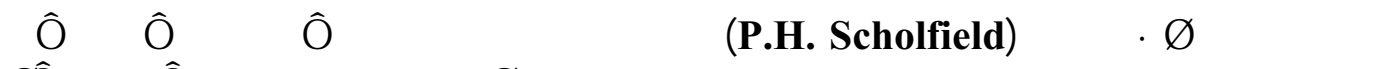

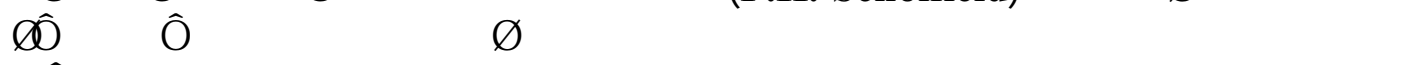

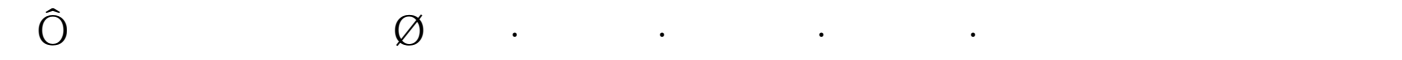

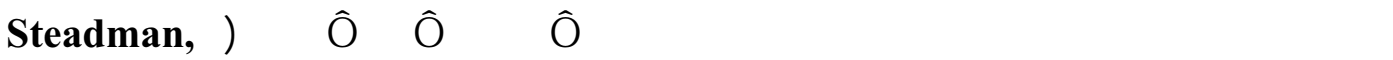

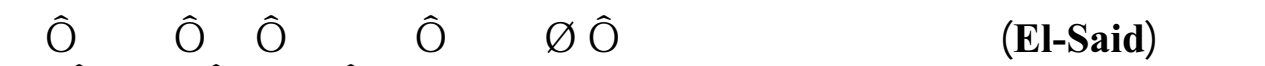
.(p.222

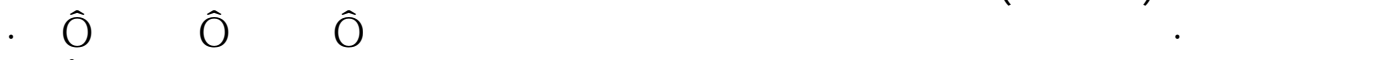

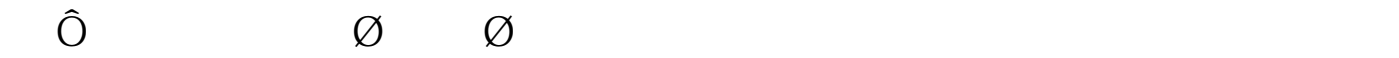
.(El-Said, p.115-127) Ŝttîgalght

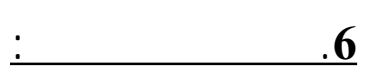

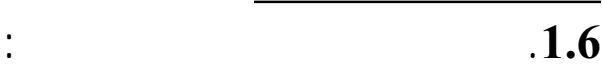

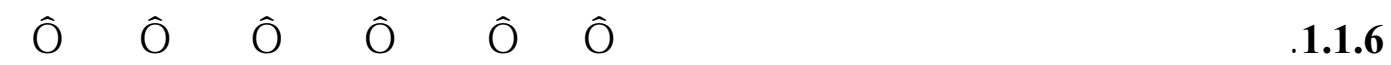

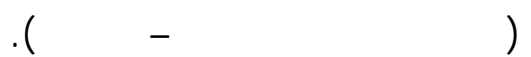

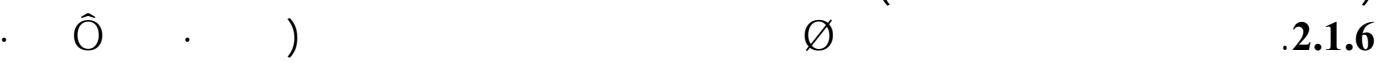

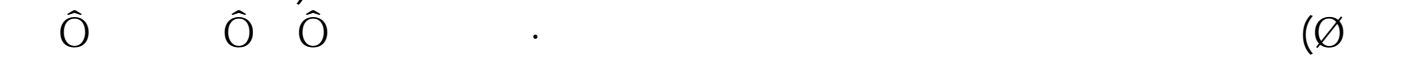

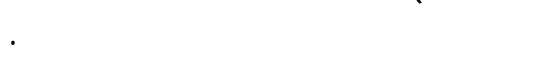

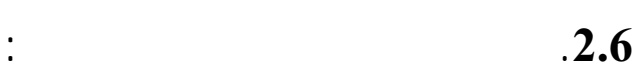

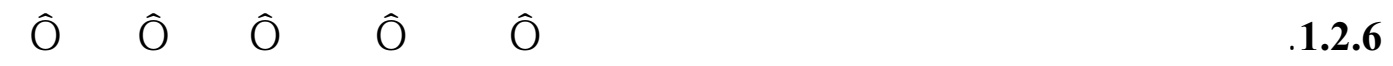
.(Ŝttîf 


\begin{tabular}{llll} 
Al-Rafidain Engineering & Vol.14 & No.2 & 2006 \\
\hline
\end{tabular}

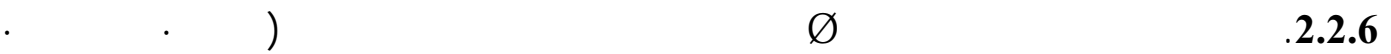

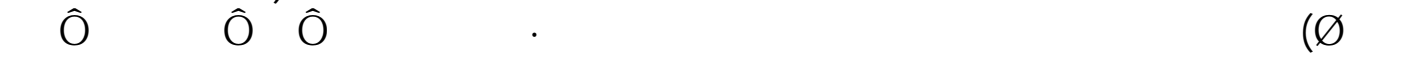

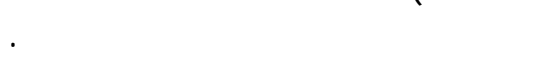

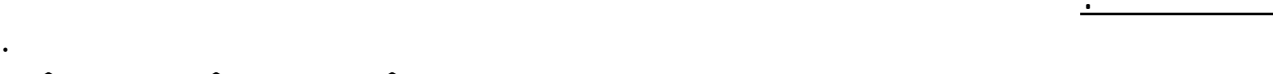

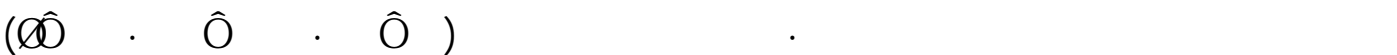

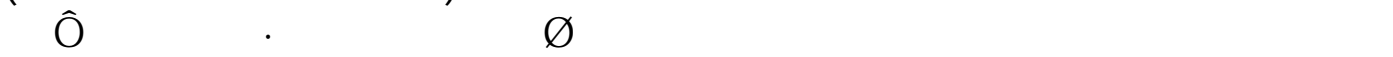

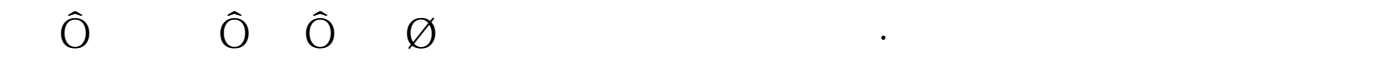

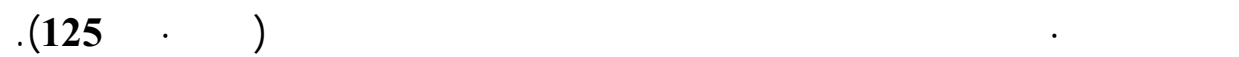

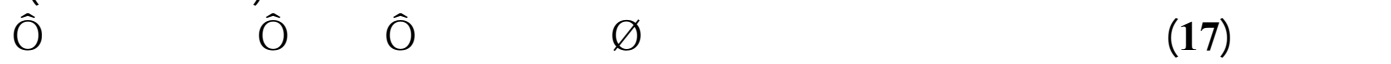

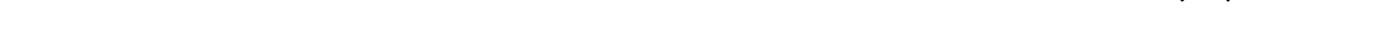

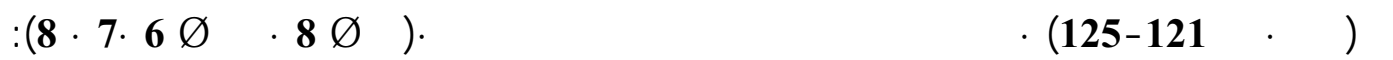

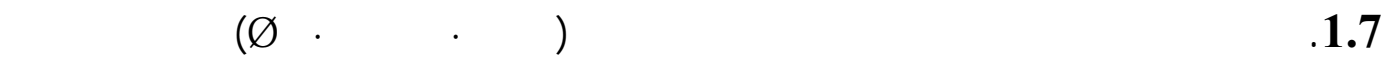

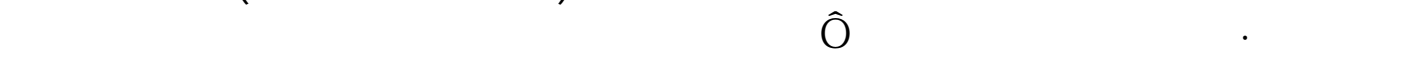

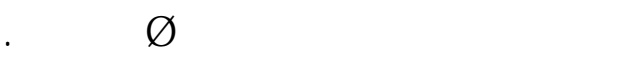

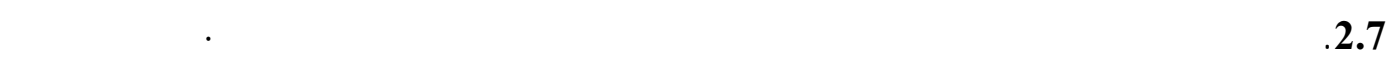

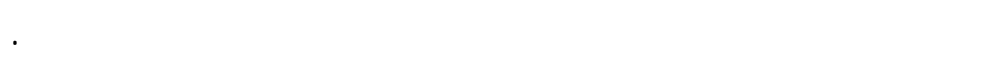

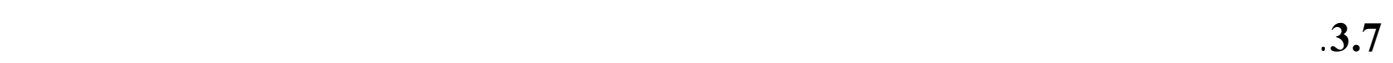

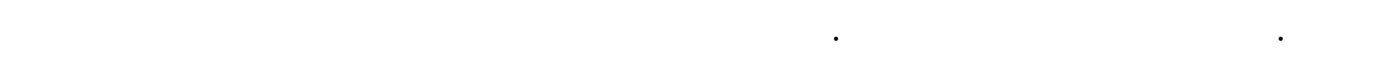

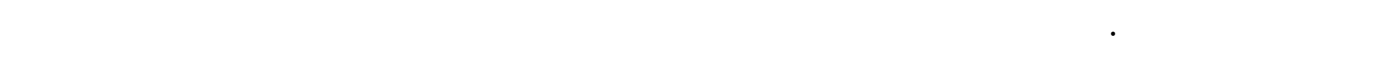

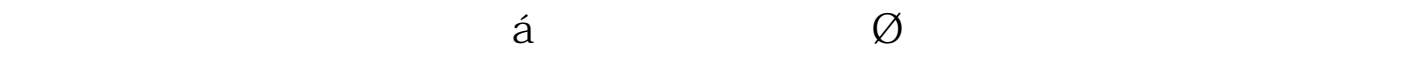

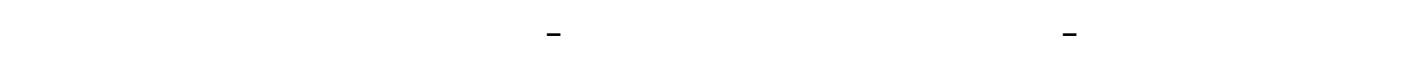

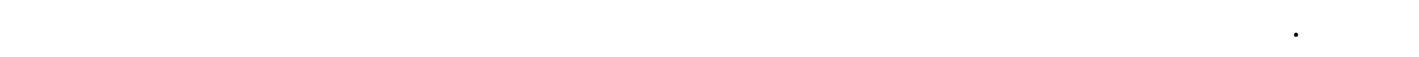

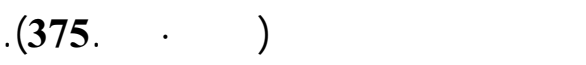

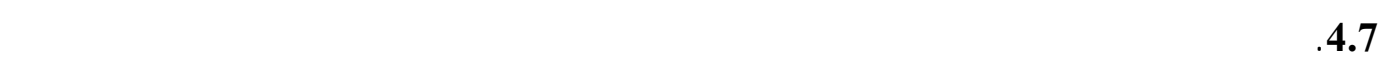

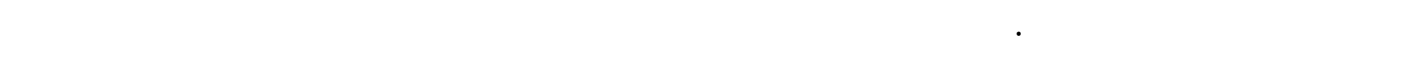

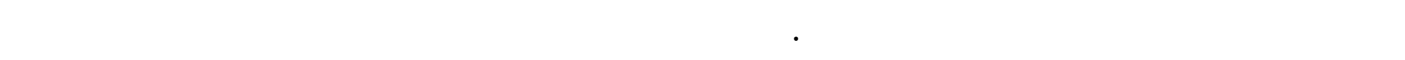

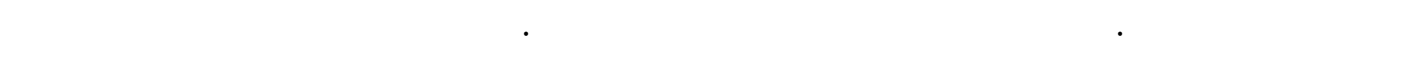

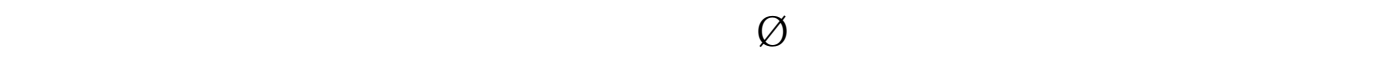

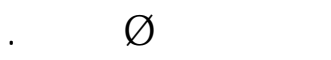

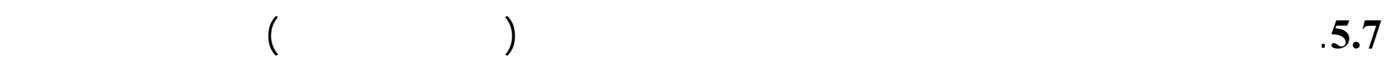

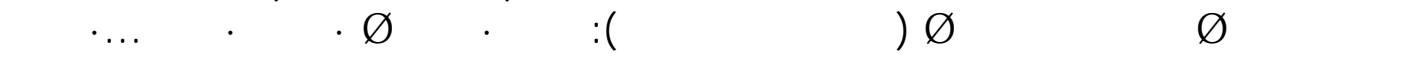

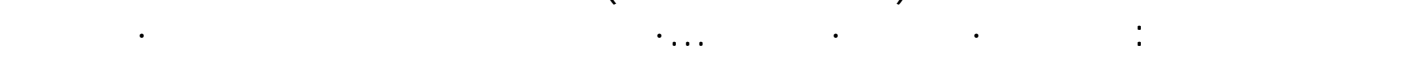




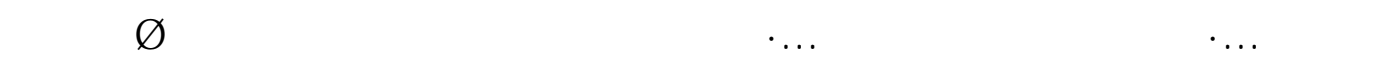

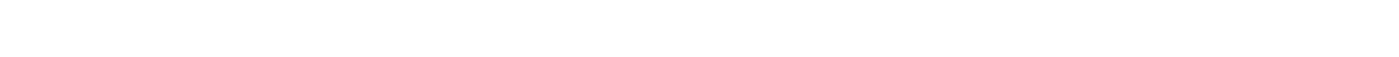

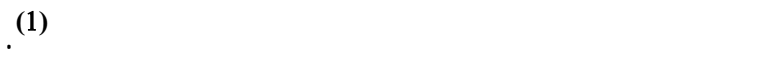

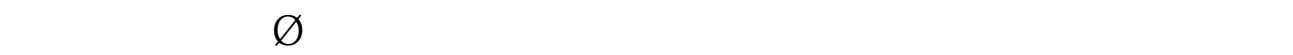

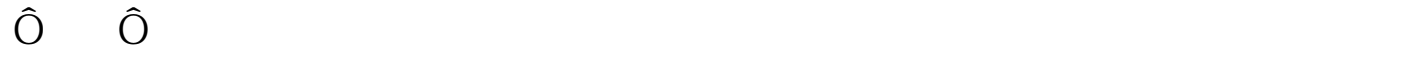

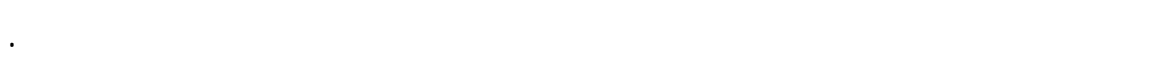

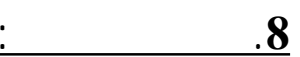

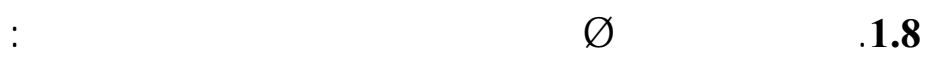

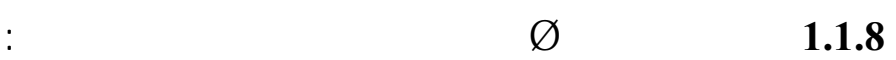

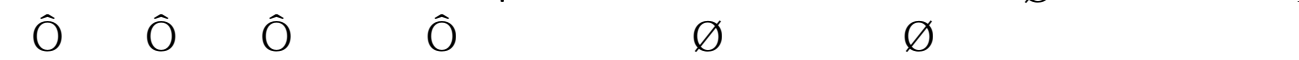

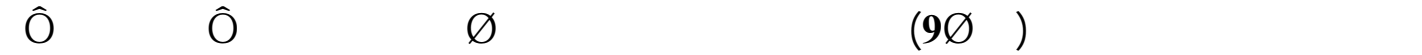

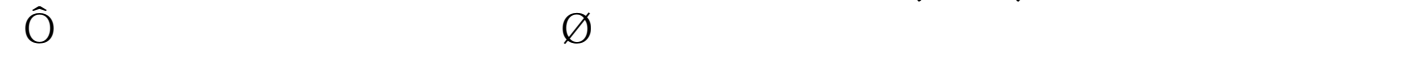

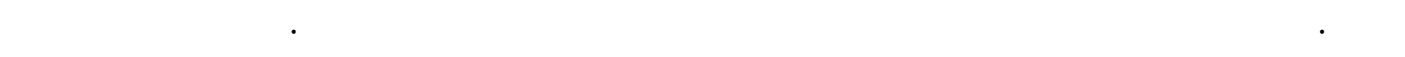

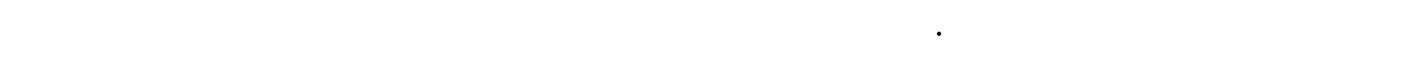

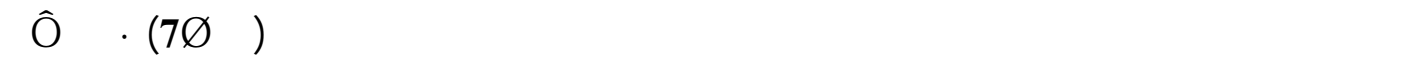
19 and đof

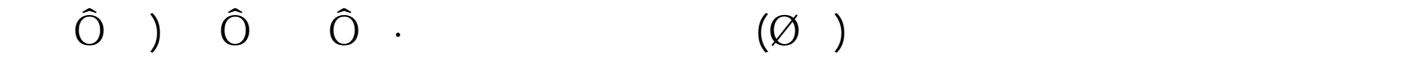

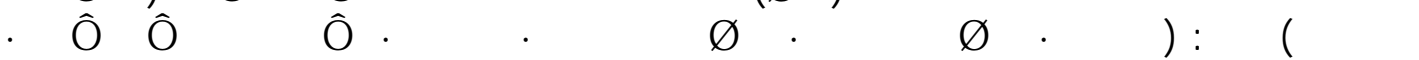

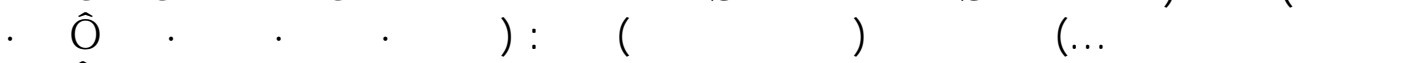
Frger ŕRÜ

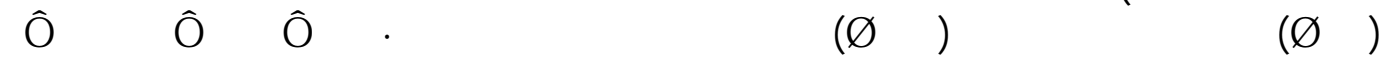

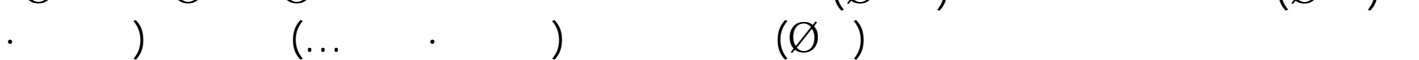

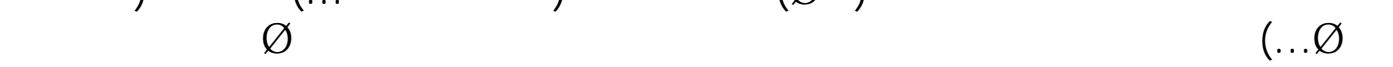

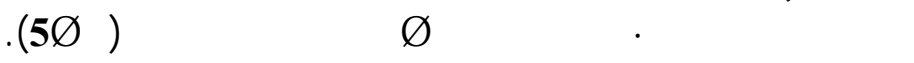

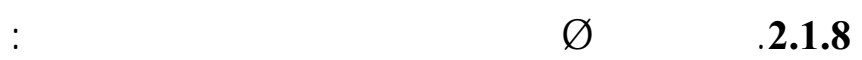

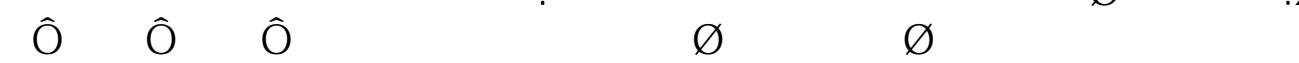

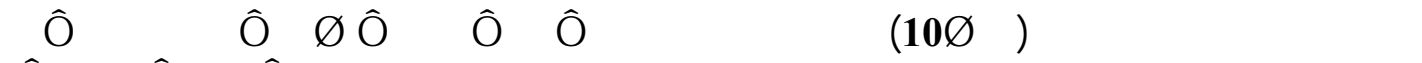

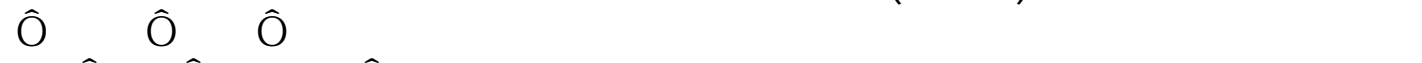

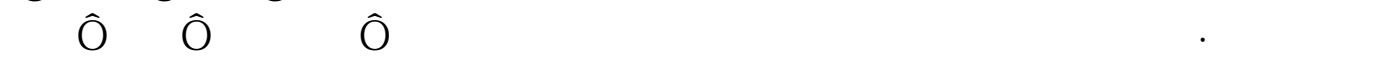

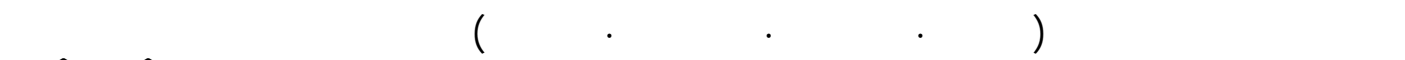

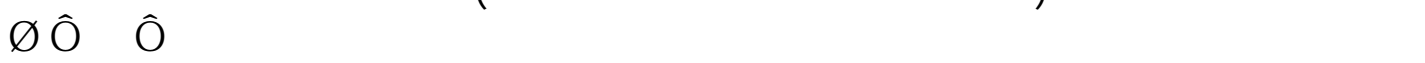

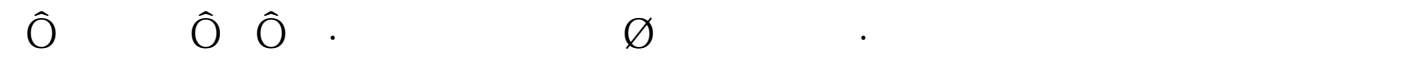

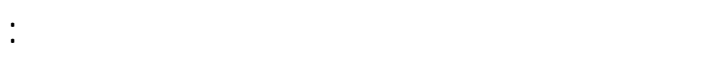

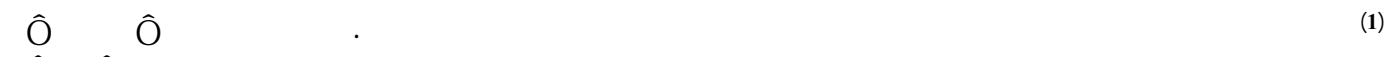

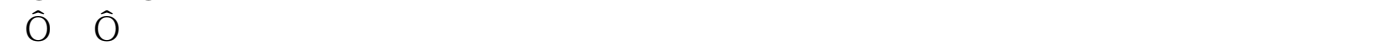

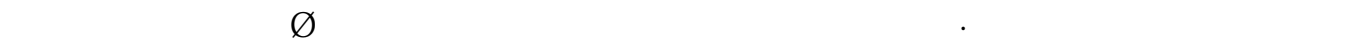




\begin{tabular}{llll} 
Al-Rafidain Engineering & Vol.14 & No.2 & 2006 \\
\hline
\end{tabular}

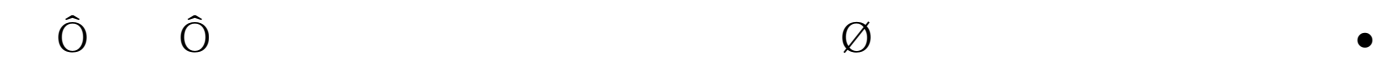

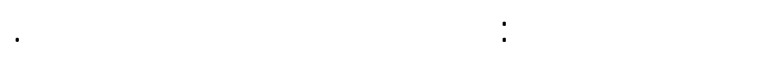

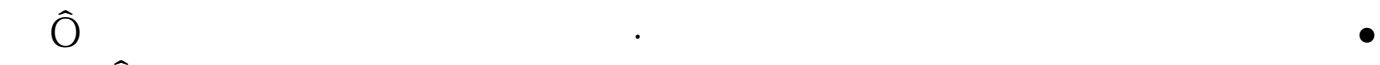

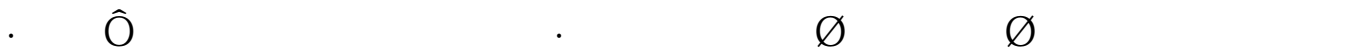
. đgg

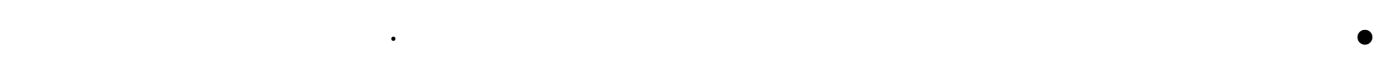

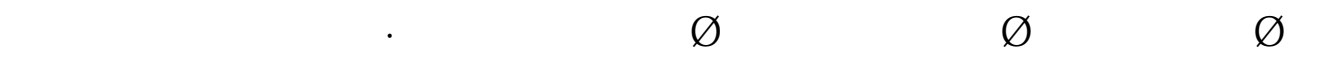

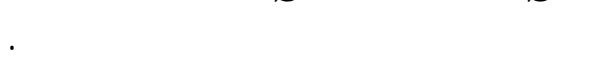

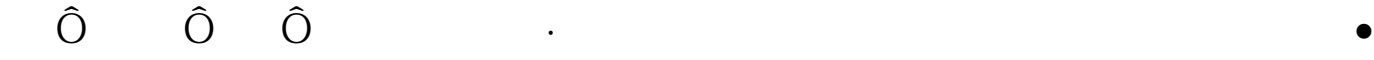

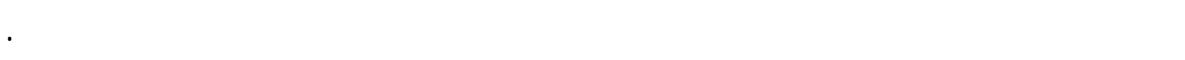

ŝว :(Minitab 11, Simulent 3.08 Fä:šł G

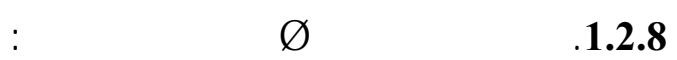

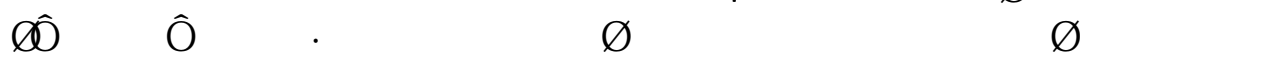

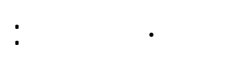

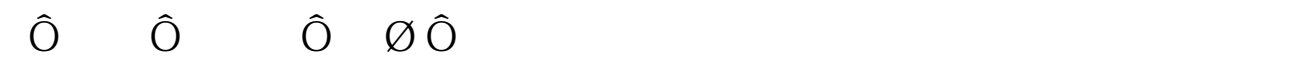

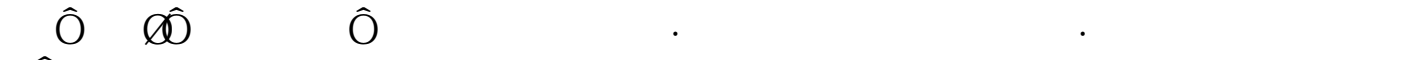

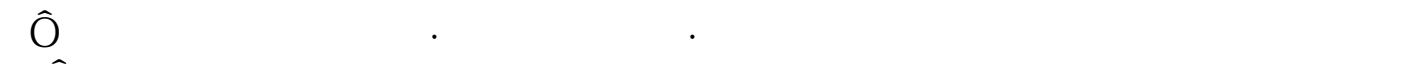

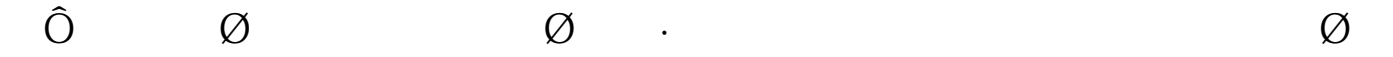
ヨgüD ǎs

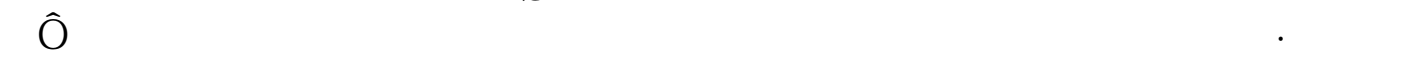

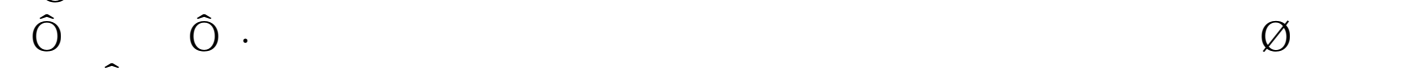

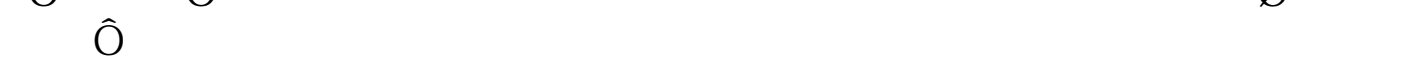

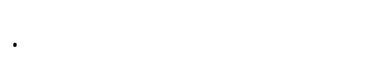

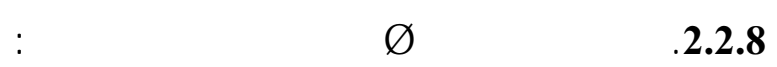

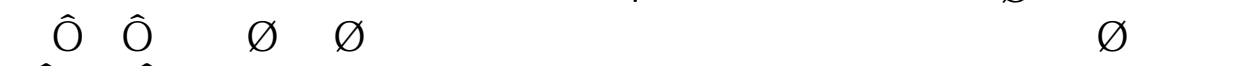

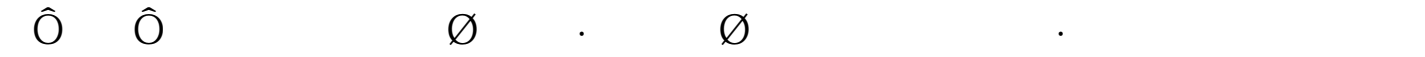

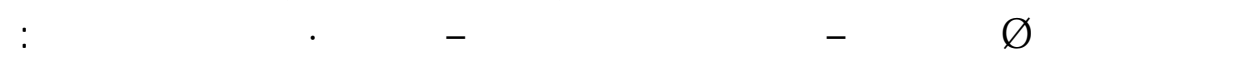

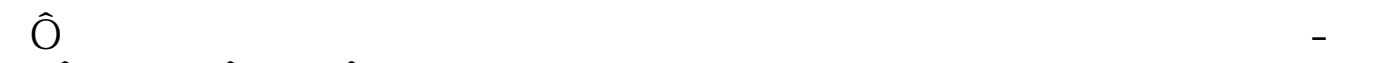

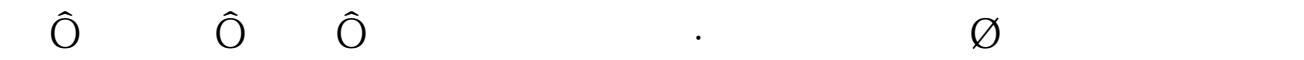

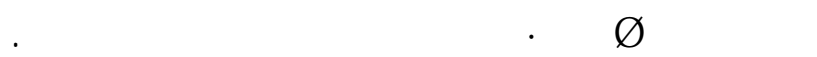

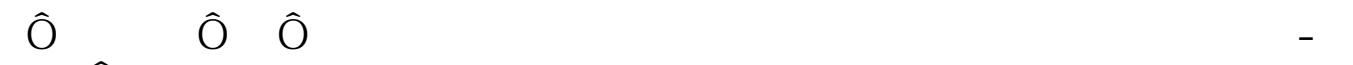

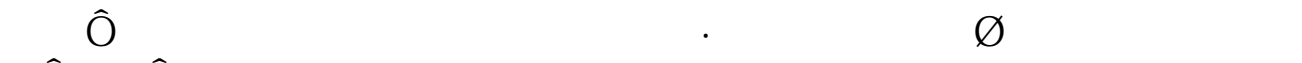

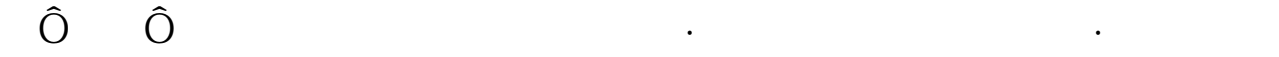

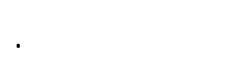




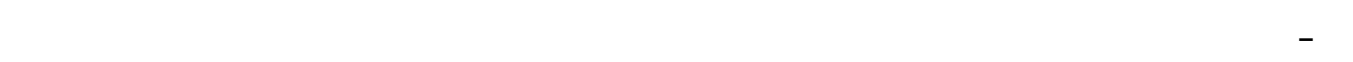

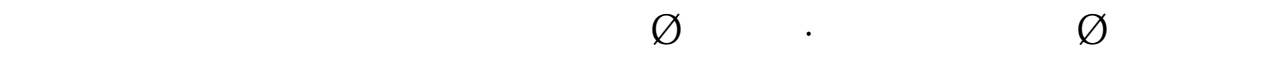

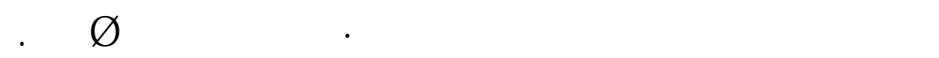

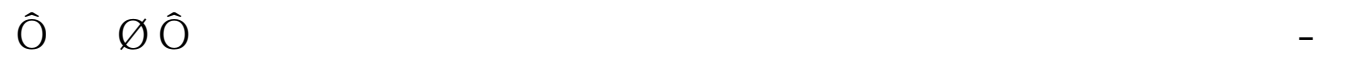

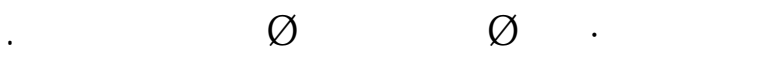

:Ř⿻

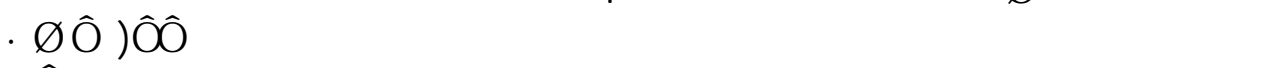

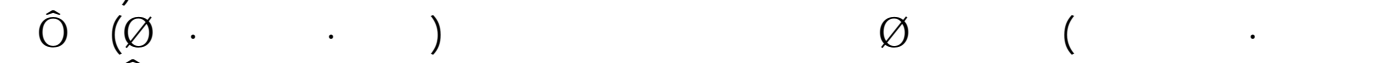

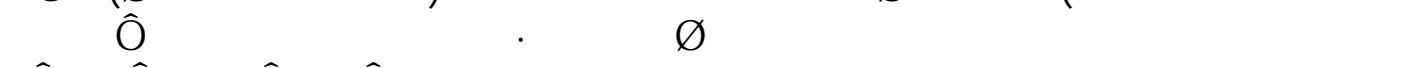

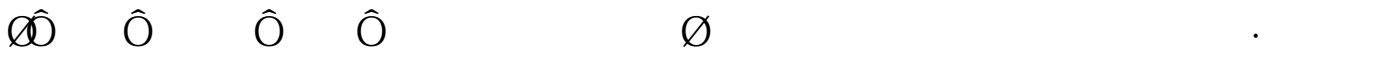

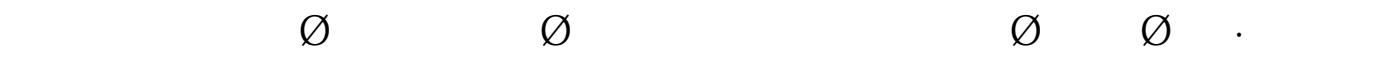

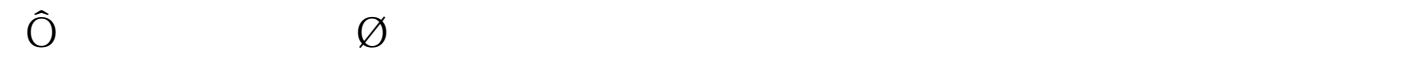

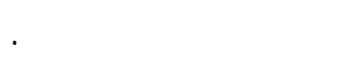

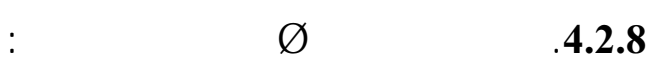

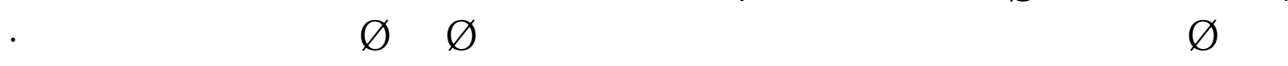

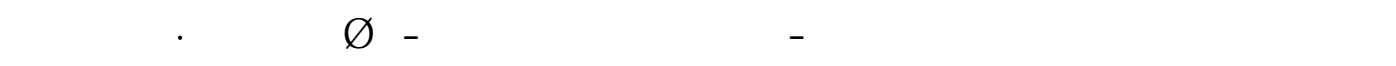

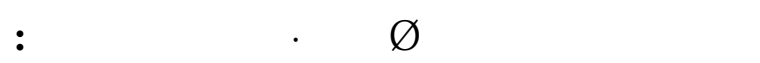

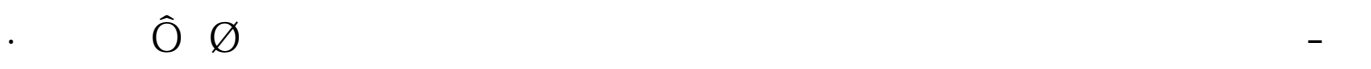

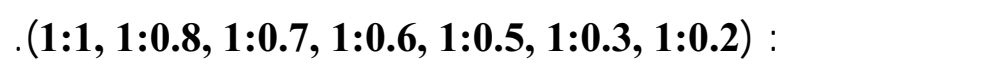

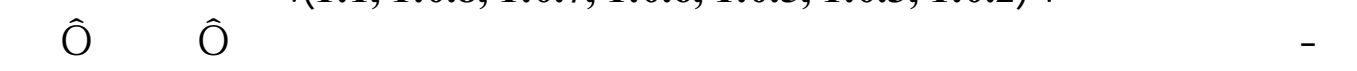

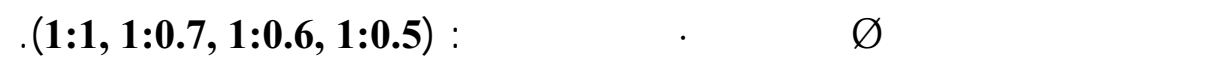

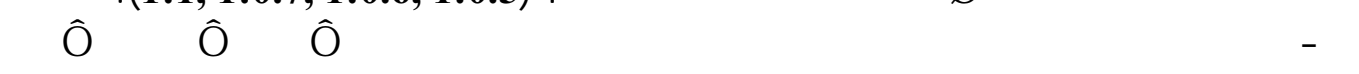

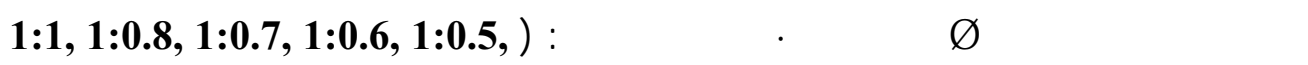
.$(1: 0.3,1: 0.2$

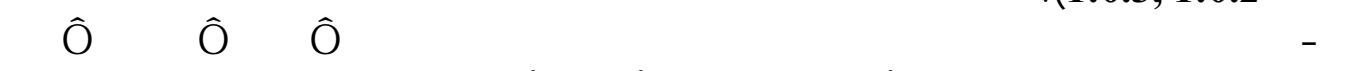

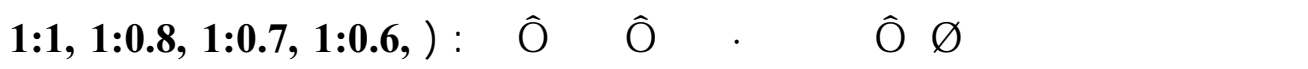
.$(1: 0.5,1: 0.3,1: 0.2$

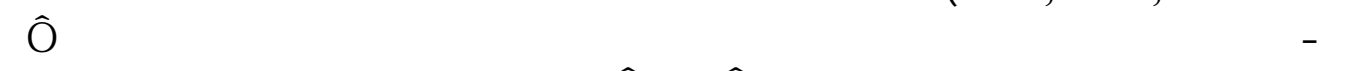

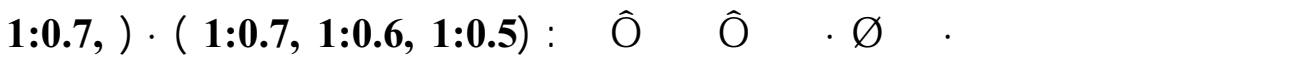

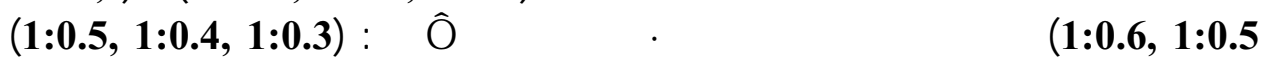

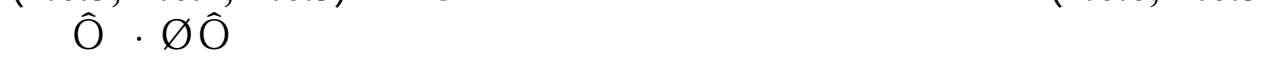

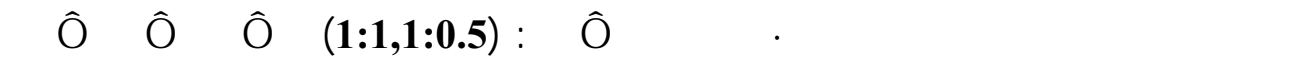

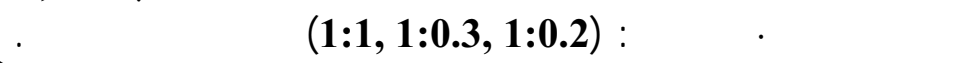

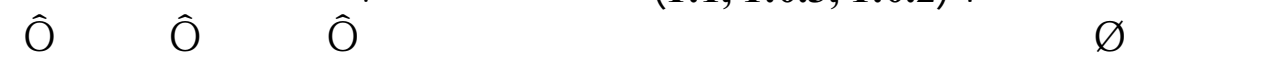

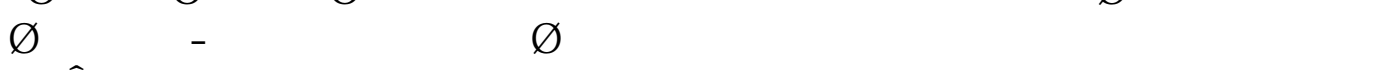

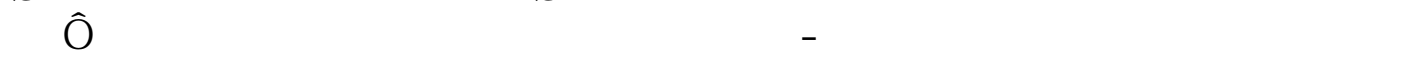

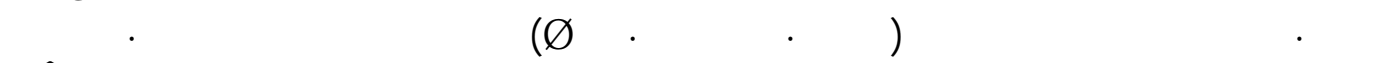
Fon ๔ :

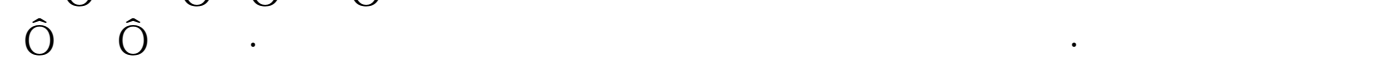




\begin{tabular}{llll} 
Al-Rafidain Engineering & Vol.14 & No.2 & 2006 \\
\hline
\end{tabular}

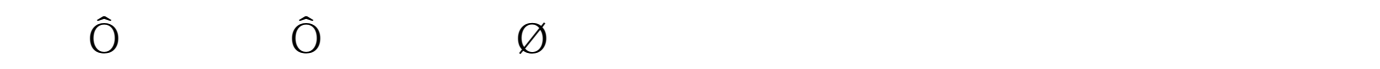

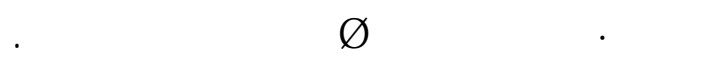

पরั :

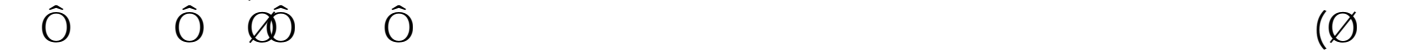

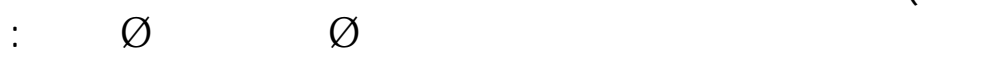

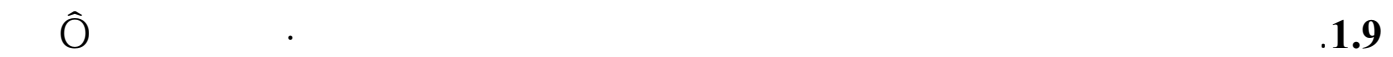

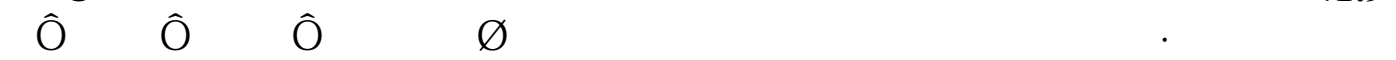

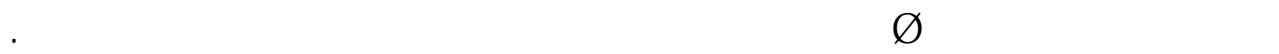

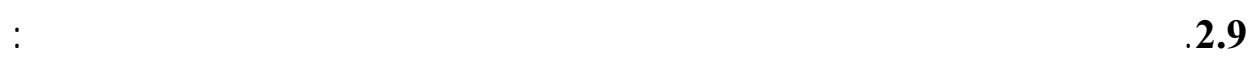

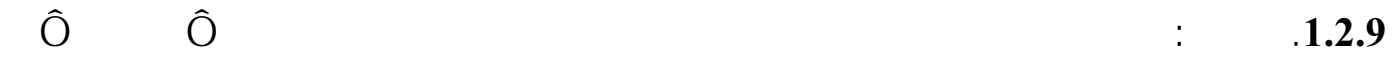

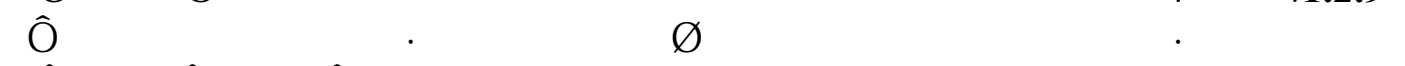

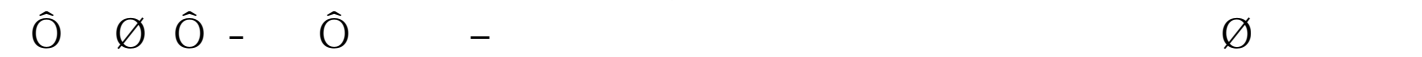

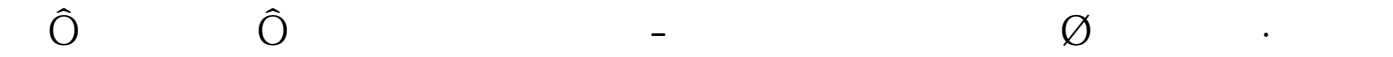

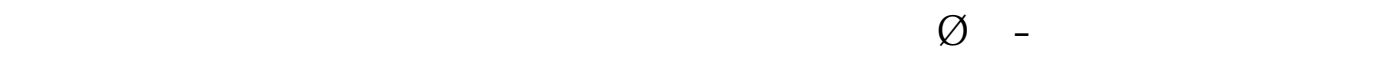

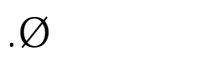

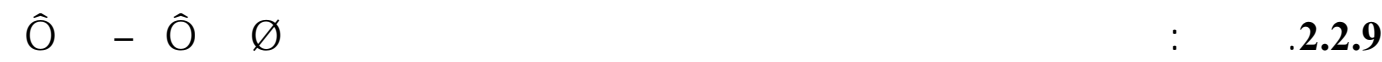

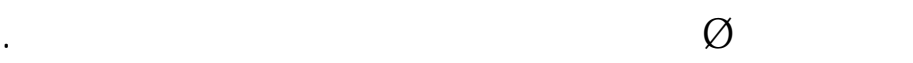

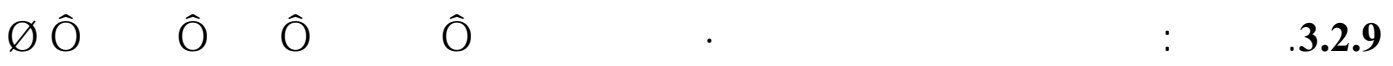

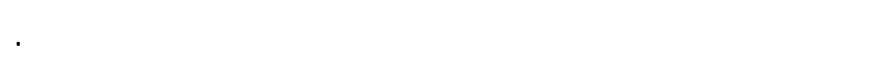

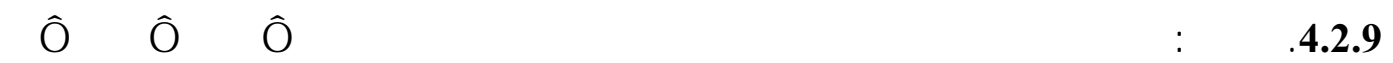

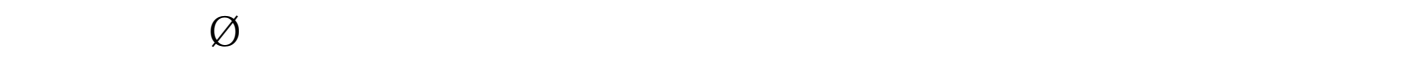

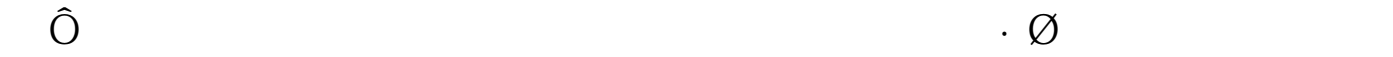

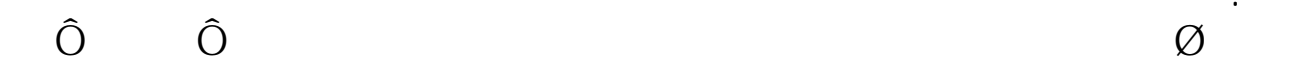
Iff ÜF

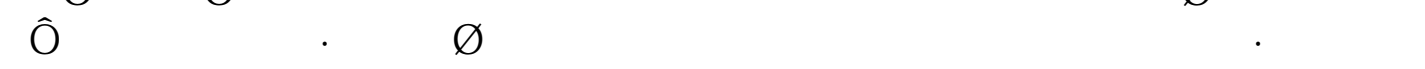

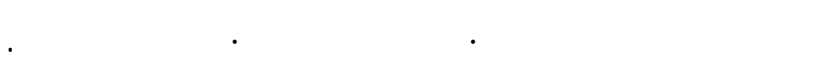

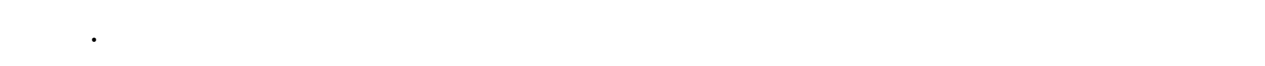

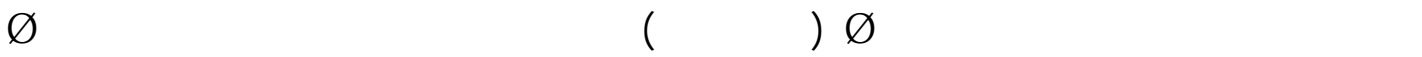

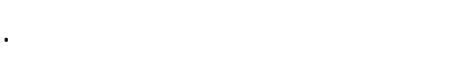




\section{ttdidirir}

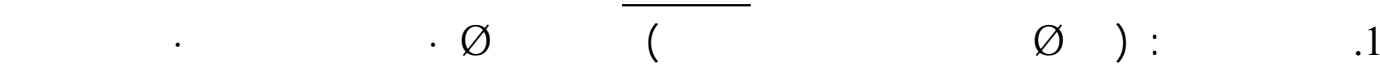

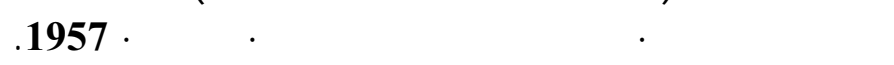

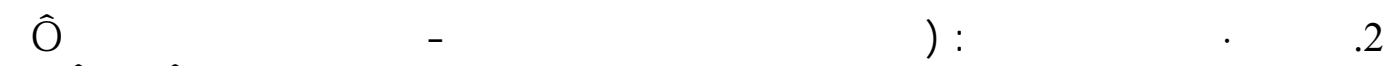
Ś $.1982 \square$ tot $\square 119$

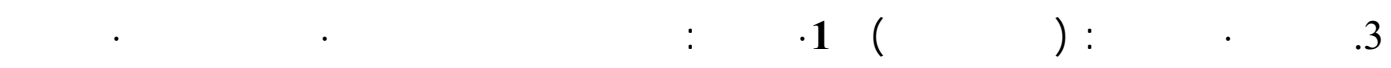

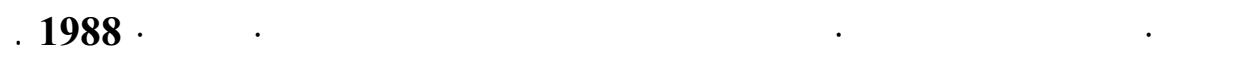

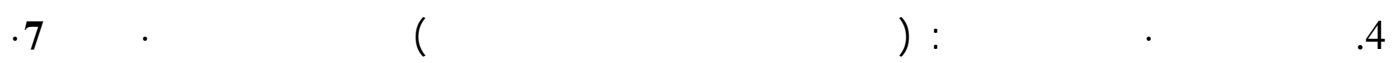
. $1993 \square$ Fa:FE

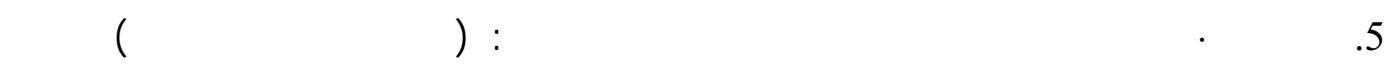

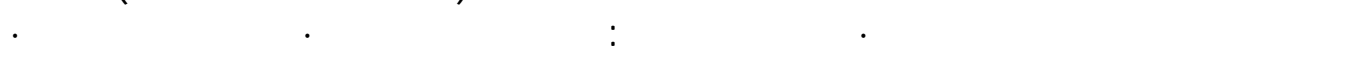
.1956 PRator

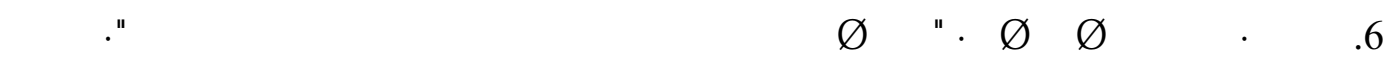

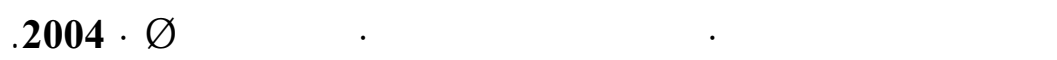

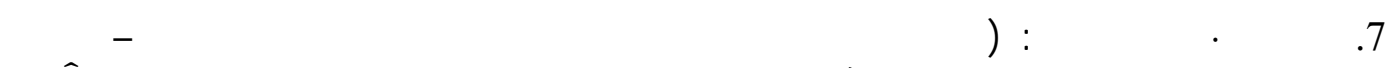

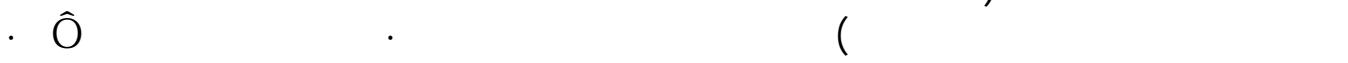

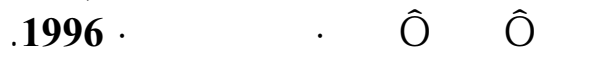

8. Ching, Francis D.K. : (Architecture: Form, Space, \& Order) Second Edition, VAN, Nostrand Reinhold, ITP, A division of international Thomson publishing Inc. U.S.A, 2002.

9. Crowe, Norman : (Nature \& The Idea Of A Man - made World) The M.I.T. Press, Cambridge, Massachusetts, London, 2003.

10. El-Said, Issam \& Parman, Ayse : (Geometric Concepts In Islamic Art) Scorpion publishing Limited World of Islam Festival Trust, Guildford, England, 1976.

11. Gedal, Najib, (The Great Mosque Of Qayrwan - Geometric Analysis Architecture And Development In Islamic World) Edited by Sultan Barakat, Institute of Advanced Architectural studies, University of York, 2003.

12. Ghyka, Matila : (The Geometry Of Art And Life) Dover publications, Inc, New York, 1977.

13. Langhein, Joachim : (On The Path To A General Proportion Theory Research Perspecture For The 21st.Century) http :/www. Design community. com / students / 4563.html, 2002.

14. Mitchell, William J. : (The Logic Of Architecture) the M.I.T. press, Cambridge mass, 1992.

15. Steadman, Philip \& March, Lional, and : (The Geometry Of Environment - An Introduction To Spatial Organization In Design) RIBA Publications Limited, London, 1971.

16. Tansey, Richard G. : (Art Through The Ages) Harcourt brace Jovavich, College publishers, 1991. 